\title{
Um olhar para o ensino de Filosofia na rede pública paulista de ensino regular
}

\author{
Jefferson Luis Brentini da Silva \\ Pesquisador na Universidade Estadual Paulista Júlio de Mesquita Filho, Araraquara, São \\ Paulo, Brasil. \\ brentini.fil@gmail.com
}

\section{Denis Domeneghetti Badia}

Professor na Universidade Estadual Paulista Júlio de Mesquita Filho, Araraquara, São Paulo, Brasil. denis@fclar.unesp.br

Recebido em 01 de abril de 2018

Aprovado em 13 de novembro de 2018

Publicado em 23 de janeiro de 2019

RESUMO: A reinserção da componente curricular Filosofia e Sociologia no ensino brasileiro em 2008 desencadeou uma série de mecanismos para tornar possível o ensino destas disciplinas; mas, será que tais demandas convergem na apropriação do saber filosófico ou são apenas mecanismos para tornar, especialmente a disciplina de Filosofia, marginal e com pouco valor para todos? Esse artigo aponta a partir de uma abordagem qualitativa enviesada no ideal e no real os possíveis caminhos do ensino de Filosofia na rede pública paulista de ensino regular. Para tanto, os objetivos são analisar a possibilidade do Currículo Oficial do Estado de São Paulo (SÃO PAULO, 2010), materializado no Material de Apoio ao Currículo do Estado de São Paulo (SÃO PAULO, 2014) e, por conseguinte, contrastar a proposta com a previsão de aulas dentro do calendário letivo de 2014, a fim de esclarecer a sua possibilidade ou não, de serem cumpridas. Como resultado evidenciou que, mesmo em situações ideais, em virtude do excesso da demanda, do curto tempo disponível para a consecução e dos processos de construção do indivíduo na sociedade é uma demanda quase impossível de ser cumprida. Palavras-chave: Filosofia; Material de Apoio ao Currículo do Estado de São Paulo; Currículo Oficial do Estado de São Paulo; Ensino Público.

\section{Introdução}

A educação desde a era clássica é considerada um bem precioso, magnífico, único e essencial, tanto para aqueles que detêm o poder quanto para aqueles que desejam conhecer, refletir, interpretar e busca e, em muitos casos, um significado para as suas vidas, para a sociedade.

Nesse sentido observa-se, desde o século XVIII, a necessidade de buscar meios para assegurar, por meio da escola, o acesso à educação que gradativamente tem ampliado esse acesso na perspectiva de abarcar a todos. 
Em virtude do afunilamento do tema aqui delineado, o foco incidirá nas políticas públicas educacionais voltadas para a rede pública de ensino do Estado de São Paulo que em meados de 90 tem como prospecto a garantia ao acesso, à permanência e a uniformidade das ações pedagógicas, dentre tais políticas destacam-se a Progressão Automática ${ }^{1}$ que, pela não reprovação dos alunos, eliminaria possibilidade de evasão escolar por conta da estigmatização da repetência bem como a possibilidade de garantir, ainda que em turnos distintos, a recuperação desse discente ao alcançar o esperado em cada ano/série; a reforma da organização da educação básica nacional ou a legislação que outorgou a obrigatoriedade escolar para crianças e adolescentes, preferencialmente nas redes públicas de ensino e o estabelecimento de um currículo e de um material orientador da prática pedagógica (SÃO PAULO, 2010; 2014).

Dessa forma, a educação paulista trilhou caminhos fulcrais no que diz respeito ao acesso à escola, porém, qual a influência destas implementações no oferecimento da disciplina de Filosofia na educação básica no formato proposto para a rede pública paulista de ensino regular?

A fim de trazer algumas reflexões sobre o tema, abordou-se de maneira qualitativa, a partir dos métodos de pesquisa bibliográfica e análise documental a obrigatoriedade da Filosofia em formato disciplinar, seu currículo e material oficial.

Quanto ao método de pesquisa bibliográfica, Gil (2002, p. 44) descreve que é "desenvolvida com base em material já elaborado, constituído principalmente de livros e artigos científicos”, enquanto Severino (2002, p. 122) discorre que a pesquisa bibliográfica é "aquela que se realiza a partir do registro disponível, decorrente de pesquisas anteriores, em documentos impressos, como livros, artigos, teses e etc.", utilizando-se de dados e fontes já pesquisadas por outros e consideradas válidas pelos seus pares.

Agora, quanto a pesquisa documental, a partir da leitura e análise de Gil (2002, p. 45-46) é possível dizer que é muito parecida com a pesquisa bibliográfica, entretanto, a "diferença entre ambas está na natureza das fontes", isto é, se "verifica os documentos conservados em arquivos de órgãos públicos e instituições privadas, tais como associações científicas, igrejas, sindicatos, partidos políticos", podendo ser diversos documentos.

Já em Severino (2002, p. 122-123) as pesquisas documentais possibilitam pensam no documento em um sentido amplo e, nesses casos "os conteúdos dos textos que ainda não tiveram nenhum tratamento analítico, são matérias primas, a partir da qual o pesquisador vai desenvolver sua investigação e análise".

A hipótese que aqui se coloca é que tais processos, decorrentes das políticas públicas militam em prol da redução do papel do educador a mero reprodutor de determinações advindas de instâncias administrativas superiores que priorizam resultados estatísticos em detrimento do efetivo ensino por parte dos professores e da aprendizagem por parte dos alunos. 


\section{Desenvolimento}

A Filosofia, tornada obrigatória em meados de 2008 e por estar ainda em processo de adequação, acaba sofrendo uma série de pré-conceituações, sobre qual seria o seu papel dentro da educação básica; assim como a sua finalidade dentro do processo de formação do indivíduo que é contemplado por tal arcabouço (BRASIL, 2006; MORAES, 2007; RODRIGUES, 2012).

Infelizmente muitas pessoas, desde alunos até professores, gestores e membros da comunidade, inclusive em sentidos perversos, acabam encarando a filosofia erroneamente a partir do senso comum sob as seguintes formas, sob a ótica de Kohan (2002) e Bittencourt (2015):

I. Como fonte de criticismo, de desvalorização daquilo que se encontra e que nos é posto;

II. Pode, também, fazer com que as pessoas que se nutrem desse arcabouço pensem que a mesma é uma fonte da verdade absoluta;

III. A filosofia pode ser calcada apenas para os debates da realidade política e social, tendo como pano de fundo a realidade que nos apetece;

IV. Pode ser elencada apenas como uma espécie de via de conhecimento dialógica, sem se calcar nas teorias sobrepostas e que complementariam tais diálogos; e, por fim,

V. Ser encarada apenas como parte da história, desmerecendo, por conseguinte, o caráter atemporal uma teoria; e, como exemplo dessa atemporalidade, podemos citar o conceito de felicidade de Aristóteles, proposto na Era de Péricles (séc. $V$ a. C.) em Atenas, pode facilmente ser aplicada nos dias de hoje, sem que para isso faça uma busca histórica sobre a importância, a causa e a consequência desta na história.

Por conta desse quadro, a Filosofia permaneceu muito distante daquilo que é: um arcabouço magnífico e primordial que busca por significados para além daquilo que nos é posto, pensado e sentido; e, por sua vez, é usualmente tratada com certo desprezo e/ou de forma deturpada de seu real sentido.

Talvez seja pela falta de atenção necessária para a implementação desta área do conhecimento, podendo ser traduzida pela falta de formações para professores de Filosofia ou pela mesma ter sido banida da educação por um longo período, por se tratar de uma disciplina que desperta a veia crítica e reflexiva do indivíduo, ou, ainda, por não ter sido, desde os meados do descobrimento do Brasil, aceita e difundida social e culturalmente, enfim, sempre foi uma área do conhecimento, especificamente aqui no Brasil, que não teve tradição, muito pelo contrário, sempre fora pensada como algo perverso, vil e pernicioso (SÁ JÚNIOR, 2010; BROCANELLI, 2012; BITTENCOURT, 2015; GONÇALVES, 2014; RODRIGUES,2012; ASPIS \& GALLO, 2009).

Daí a importância da Filosofia, do ato de filosofar e, é claro, da sua reinserção no cenário educacional de nosso país: para despertá-lo a autonomia, a autenticidade, a criticidade e, por conta disso, a plena formação do indivíduo para a sociedade.

Em virtude do recorte deste artigo e da importância de conhecer os recursos disponíveis para a oferta, concreção e assimilação dos conteúdos, competências e 
habilidades a partir daqui discorrerá sobre o que é imposto para ensinar em Filosofia na educação básica através do disposto no currículo e material oficiais da educação pública paulista (SÃO PAULO 2010; 2014) e, por fim, o tempo disponível para a consecução das aulas, como base o calendário do ano letivo de $2014^{2}$ para, então, se posicionar quanto à possibilidade de executar tudo o que é previsto legalmente, as suas demandas.

Com o retorno da Filosofia enquanto componente curricular em caráter obrigatório, em 2006, subentende-se o seu reconhecimento e valor social e cultural que tal via do conhecimento possui na constituição da educação e da formação de um sujeito pensante e crítico sobre a sua posição ante ao mundo bem como sobre o mundo em si.

Nesse sentido, tal componente não só permite, mas também dinamiza o debate interdisciplinar, isto sem deixar de lado a contemplação dos conteúdos especificamente filosóficos, podendo ser abordados tanto de maneira histórica quanto por temáticas.

Por conseguinte, a Secretaria Estadual de Educação do Estado de São Paulo (SEE-SP) propôs em 2008, e que vigora até hoje, um currículo básico para todas as escolas da rede pública paulista de ensino regular nos níveis de Ensino Fundamental (Ciclo II) e Ensino Médio.

Tal processo partiu da necessidade de montar um currículo único que suprisse aquilo que era esperado pela população, descritos nas diretrizes curriculares e, também como um processo de regulação e regulamentação da educação estadual a partir das políticas públicas para este setor da sociedade a níveis nacionais e internacionais (SÃO PAULO, 2010, p.15), valorando pelas experiências práticas e dos conhecimentos teóricos que convergiam na imprescindibilidade da criação de um currículo único para uma escola de massa ${ }^{3}$.

O Currículo Oficial do Estado de São Paulo (SÃO PAULO, 2010) é fundamental para a prática pedagógica dos professores da rede pública paulista de ensino regular, pois é a partir deste instrumento que se apontam quais recursos didáticos e paradidáticos devem ser priorizados para desenvolver e fortalecer os conteúdos e habilidades prospectados para cada bimestre e ano letivo. Além disso, neste recurso são propostos os meios de avaliação, reforço, nivelamento e recuperação para a verificação e assimilação dos conteúdos e habilidades ali dispostos.

Outro ponto que consolida o seu grau de importância neste segmento de ensino é que a partir das capacidades ali prospectadas para cada bimestre, série e disciplina que o Sistema de Avaliação de Rendimento Escolar do Estado de São Paulo (SARESP) 4 é formulado anualmente e oferecido a fim de mensurar a qualidade do ensino (SÃO PAULO, 2010, p.22).

Para tanto, o Currículo Oficial do Estado de São Paulo (SÃO PAULO, 2010a, p.10-24) tem como objetivos principais: a escola que aprende, na perspectiva da constante atualização e aprendizado de todas as pessoas ali envolvidas; currículo como espaço de cultura, por nele estar incutido elementos de (re) produção cultural; competências como cerne no processo de ensino/ aprendizagem; a primazia nas competências de leitura e escrita; o uso de competências para proporcionar uma eficaz aprendizagem; estreitamento do ensino com o mundo do trabalho. 
Conforme o Quadro 1, segundo o Currículo Oficial do Estado de São Paulo (SÃO PAULO, 2010), esse é o percurso que deve ser seguido para que os alunos tenham condições para filosofar e ter conhecimento suficiente para conhecer, a fundo, tal componente curricular.

Quadro 1: a Filosofia a partir do Currículo do Estado de São Paulo

\begin{tabular}{|c|c|}
\hline $1^{a}$ série & $\begin{array}{l}\text { Porquê estudar Filosofia? As áreas da Filosofia; A Filosofia e outras } \\
\text { formas de conhecimento (Mito, Cultura, Religião, Arte, Ciência); } \\
\text { Introdução à Filosofia Política (Teorias do Estado; Socialismo, anar- } \\
\text { quismo e liberalismo); Filosofia Política (Democracia e cidadania: } \\
\text { origens, conceitose dilemas; Desigualdade sociale ideológica; Demo- } \\
\text { cracia e justiça social; os direitos humanos; Participação política). }\end{array}$ \\
\hline $2^{\mathrm{a}}$ série & $\begin{array}{l}\text { Introdução à ética (O eu racional; Autonomia e liberdade; Intro- } \\
\text { dução à Teoria do Indivíduo (John Locke, Jeremy Bentham } \\
\text { e Stuart Mill); tornar-se indivíduo (Paul Ricoeur e Michel } \\
\text { Foucault); Condutas massificadas; Alienação moral; Filosofia, } \\
\text { Política e Ética (Humilhação; velhice e racismo; Homens e } \\
\text { mulheres; Filosofia e educação); Desafios éticos contemporâ- } \\
\text { neos; A Ciência e a condição humana; Introdução à Bioética. }\end{array}$ \\
\hline $3^{a}$ série & $\begin{array}{l}\text { O que é Filosofia (Superação de preconceitos em relação à Filo- } \\
\text { sofia e definição e importância para a cidadania; O homem como ser } \\
\text { de natureza e de linguagem); Características do discurso filosófico } \\
\text { (Comparação com o discurso religioso; O homem como ser político; } \\
\text { A desigualdade entre os homens como desafio da política); Carac- } \\
\text { terísticas do discurso filosófico (Comparação com o discurso cien- } \\
\text { tífico; Três concepções de liberdade; Libertarismo, determinismo e } \\
\text { dialética); Características do discurso filosófico (Comparação com o } \\
\text { discurso da literatura; Valores contemporâneos que cercam o tema } \\
\text { da felicidade e das dimensões pessoais e sociais da felicidade) }\end{array}$ \\
\hline
\end{tabular}

Fonte: Elaborado pelo autor a partir de São Paulo (2010).

Para tanto, é necessário a leitura, o debate e as possíveis interpretação das diversos tipologias textuais propostas ante o percurso projetado no Material de Apoio ao Currículo do Estado de São Paulo (SÃO PAULO, 2014).

Sob tal ponto de vista, a Filosofia tem por finalidade a orientação e reflexão da contemporaneidade e, ao mesmo tempo, das relações histórico-sociais e do universo material e simbólico (re)produzido na sociedade.

E que, por conseguinte, eleva a educação para um patamar político-existencial que transcenda o cenário que conflua a meras transmissões e aquisições de arcabouços, realizados de modo mecânico e inconsciente.

Deste modo, as práticas pedagógicas têm como norte a (re)produção de desafios e discussões que estão inseridas na sociedade, em especial, a partir das inovações tecnológicas que permeiam a mesma, como as redes de comunicação e de levantamento de arcabouços que (co)existem dentro e fora do espaço escolar, como a internet.

Sob a ótica do currículo oficial, o professor de Filosofia deve ser o mediador de um processo de ensino-aprendizagem cuja finalidade é a de formar cidadãos habilitados a (re) conhecer e (re) solver os mais diversos problemas e desafios que são oferecidos durante 0 processo de ensino/ aprendizagem. 
Nesse processo de concreção, edificação e fortalecimento pautado na construção do saber é de suma importância à adoção de metodologias estejam aquém dos recursos didáticos tidos tradicionais, a fim de que o docente motive e sensibilize seus alunos quanto à importância de se estudar, construir e difundir os saberes, tal qual o próprio processo de conhecer, do aprender.

Carece então, conforme os registros presentes no currículo oficial (SÃO PAULO, 2010) que o docente esteja em constante atualização e concomitante a isso preservar e consolidar o seu conhecimento da área e dos mecanismos voltados para a prática docente, perpetuando, assim, sua autonomia ante ao processo de mediação entre os saberes, os alunos e a sociedade.

Por fim, o Currículo Oficial do Estado de São Paulo (SÃO PAULO, 2010) chama a atenção sobre a necessidade do aproveitamento e da utilização do Material de Apoio ao Currículo (SÃO PAULO, 2014) integralmente considerando as realidades e contextos dentro das especificidades de cada região, local e instituição escolar e que tal recurso é de suma importância uma vez que, a partir da utilização correta desse material, os discentes estarão aptos e capazes para a articulação, desenvolvimento, construção, (re) produção do conteúdo esperado para cada Situação de Aprendizagem $(\mathrm{SA})^{5}$ proposta.

Por sua vez, o Material de Apoio ao Currículo do Estado de São Paulo (SÃO PAULO, 2014) é fragmentado por SAs e que também é alargado e disponível por etapas, conhecimentos priorizados, metodologias propostas, sistemas de avaliação, previsão de aulas que são necessárias para execução das SAs, assim como formas de recuperação, caso o discente necessite, e, considerações finais sobre a finalidade desse material, isto é, nele há uma série de orientações pedagógicas e com base no Currículo Oficial do Estado de São Paulo (SÃO PAULO, 2010).

Nesse sentido, o Material de Apoio ao Currículo do Estado de São Paulo (SÃO PAULO, 2014) é a materialização daquilo que é posto no Currículo Oficial do Estado de São Paulo e que, além disso, é largamente utilizado pela rede pública paulista de ensino regular para a concreção de todo o conteúdo, competências e habilidades, a partir das práticas pedagógicas dos professores.

Diante de sua primordialidade no processo de ensinar e aprender a Filosofia na rede pública paulista de ensino regular, é que a seguir exporá o que é determinado por este documento orientador das práticas pedagógicas para, então, ponderar acerca da sua viabilidade ou não.

Para tanto, será exposto o percurso que é definido pelo Material de Apoio ao Currículo do Estado de São Paulo (SÃO PAULO, 2014), etapas e atividades estabelecidas por esse material, a fim de apontar todo o percurso docente nos anos/séries em que a Filosofia, enquanto disciplina obrigatória da educação média da rede pública paulista de ensino regular.

No primeiro ano, a ideia inicial é a de sensibilizar os discentes sobre o que é Filosofia, a sua importância para a constituição do indivíduo, tanto objetiva quanto subjetivamente, além da reflexão sobre a Filosofia, o filosofar e o ensino da Filosofia, depois disso, disponibilizar os instrumentos de pesquisa em História da Filosofia. 
Depois dessa etapa, o primeiro bimestre, de apresentação geral da disciplina é proposto que seja exposta as áreas da filosofia, sensibilizando os discentes sobre cada uma delas e a presença das mesmas nas vidas de todos e, depois desse panorama geral de cada uma delas, explorar, de modo mais acurado, a Filosofia da ciência, a Filosofia da religião, a Filosofia da cultura, a filosofia da arte e a Filosofia política.

Busca-se, para tanto, as competências e habilidades tidas como necessárias para o aprofundamento dos arcabouços acima citados e, nesse sentido, as atividades propostas cotejam aprofundar o estudo e a compreensão de textos filosóficos, promover debates sobre tais temas, pesquisas individuais e em grupo, a fomentação de um glossário filosófico, a confecção de relatórios, fichas de observação e seminários para serem apresentados no decorrer das aulas. A seguir é exposta de maneira quantitativa a distribuição dos conteúdos, competências e habilidades por cada SA dispostos no Material Oficial de Apoio ao Currículo do Estado de São Paulo (SÃO PAULO, 2014).

Quadro 2: Disposição dos conteúdos, habilidades e competências do $1^{\circ} \mathrm{EM}$

\begin{tabular}{|c|c|c|c|c|c|}
\hline \multicolumn{6}{|c|}{ Material de Apoio ao Currículo de São Paulo - $1^{a}$ série do Ensino Médio } \\
\hline \multicolumn{6}{|c|}{ Filosofia } \\
\hline \multicolumn{6}{|c|}{ Conteúdos (C), Competências e Habilidades (C/H) abrangidos por cada S.A } \\
\hline \multirow[t]{2}{*}{ Vol. 1} & SA1 2ce $7 \mathrm{c} / \mathrm{h}$ & $\mathrm{SA} 2$ 4c e $4 \mathrm{c} / \mathrm{h}$ & SA3 $7 \mathrm{c}$ e $3 \mathrm{c} / \mathrm{h}$ & SA4 9c e $8 \mathrm{c} / \mathrm{h}$ & $43 c$ e $41 \mathrm{c} / \mathrm{h}$ \\
\hline & SA5 7ce $7 \mathrm{c} / \mathrm{h}$ & SA6 $5 c$ e 2 c/h & SA7 $5 c$ e $4 \mathrm{c} / \mathrm{h}$ & SA8 $4 \mathrm{c}$ e $6 \mathrm{c} / \mathrm{h}$ & \\
\hline \multirow[t]{2}{*}{ Vol. 2} & SA12ce $7 \mathrm{c} / \mathrm{h}$ & SA2 $3 c$ e $3 c / h$ & SA3 $6 c$ e $1 \mathrm{c} / \mathrm{h}$ & SA4 $7 \mathrm{c}$ e $5 \mathrm{c} / \mathrm{h}$ & $27 c$ e $23 \mathrm{c} / \mathrm{h}$ \\
\hline & SA5 3c e $2 \mathrm{c} / \mathrm{h}$ & SA6 $4 \mathrm{c}$ e $2 \mathrm{c} / \mathrm{h}$ & SA7 1c e $2 \mathrm{c} / \mathrm{h}$ & SA8 $1 \mathrm{c}$ e $1 \mathrm{c} / \mathrm{h}$ & \\
\hline \multicolumn{6}{|c|}{ Projeção de Aulas dadas por bimestre, em 2014} \\
\hline \multicolumn{2}{|c|}{$1^{\circ}$ Bimestre } & $2^{\circ}$ Bimestre & $3^{\circ}$ Bimestre & \multicolumn{2}{|c|}{$4^{\circ}$ Bimestre } \\
\hline \multicolumn{2}{|c|}{18 aulas } & 20 aulas & 16 aulas & \multicolumn{2}{|c|}{16 aulas } \\
\hline
\end{tabular}

Fonte: Elaborado pelo autor a partir de São Paulo (2014) e Caderno de Campo.

O Quadro 2, assim como os Quadros 3 e 4 apresentam uma análise sobre tudo aquilo que é requerido (conteúdos, competências, habilidades e situações de recuperação) dentro de cada SA e que, por sua vez, por bimestre foram delimitados quatro (4) SAs ${ }^{6}$ diante das metas propostas e, por conseguinte, é possível constatar que há uma série de competências e habilidades a serem alcançadas por todos, respeitando os limites de todos os alunos.

Por conseguinte, durante o trajeto referente a essa série do Ensino Médio é apresentado alguns temas filosóficos pertinentes há muito tempo na História da Filosofia e que exigem maior pensamento reflexivo e filosófico dos discentes.

Pontos como a fundação do eu e a desconstrução da realidade sob a ótica de Descartes; conceitos fundamentais sobre a Ética, a moral, a liberdade e a autonomia, sob a égide da Ética Deontológica e da Ética da Virtude; Teorias de 
Introdução do Indivíduo e o que constitui um indivíduo, o que determina e precisa a fundação e o desenvolvimento do ser, em releituras de Foucault e Ricoeur. Ainda no primeiro volume, é proposto que os discentes investiguem conceitos fundamentais da Filosofia do século $X X$, as condutas massificadas, Indústria Cultural e os processos de alienação moral.

Por sua vez, no segundo volume os discentes cotejam questões do nosso cotidiano, tais como: o preconceito, a velhice, o racismo e a desigualdade de gênero e a educação. Depois disso, introduz conceitos da Bioética, da técnica e, por fim, as teorias de Hannah Arendt, especificamente sobre a condição humana e a banalidade do mal.

Para tanto, é necessário o fortalecimento de competências ligadas à escrita, a leitura e a oralidade a partir da confecção de redações dissertativas, pesquisas, relatórios, leitura de textos, preenchimento de tabelas, discussões e seminários. O Quadro 3 aponta de maneira quantitativa os conteúdos, competências e habilidades esperadas para o segundo ano do ensino médio e a quantidade de aulas que são oferecidas para o cumprimento deste percurso.

Quadro 3: Disposição dos conteúdos, habilidades e competências do $2^{\circ} \mathrm{EM}$

\begin{tabular}{|c|c|c|c|c|c|}
\hline \multicolumn{6}{|c|}{ Material de Apoio ao Currículo de São Paulo $-2^{a}$ série do Ensino Médio } \\
\hline \multicolumn{6}{|c|}{ Filosofia } \\
\hline \multicolumn{6}{|c|}{ Conteúdos (C), Competências e Habilidades (C/H) abrangidos por cada S.A } \\
\hline \multirow[t]{2}{*}{ Vol. 1} & SA1 4c e $4 \mathrm{c} / \mathrm{h}$ & SA2 $8 \mathrm{c}$ e $2 \mathrm{c} / \mathrm{h}$ & SA3 $1 \mathrm{c}$ e $3 \mathrm{c} / \mathrm{h}$ & SA4 $5 \mathrm{c}$ e $6 \mathrm{c} / \mathrm{h}$ & \multirow[t]{2}{*}{$48 \mathrm{c}$ e $27 \mathrm{c} / \mathrm{h}$} \\
\hline & SA5 $7 c$ e $3 \mathrm{c} / \mathrm{h}$ & SA6 10c e $3 \mathrm{c} / \mathrm{h}$ & SA7 8 c e $3 \mathrm{c} / \mathrm{h}$ & SA8 5 c e $3 \mathrm{c} / \mathrm{h}$ & \\
\hline \multirow[t]{2}{*}{ Vol. 2} & SA1 $3 c$ e $3 \mathrm{c} / \mathrm{h}$ & SA2 $2 c$ e $3 \mathrm{c} / \mathrm{h}$ & SA3 $2 c$ e $3 \mathrm{c} / \mathrm{h}$ & SA4 $3 c$ e 2 c/h & \multirow[t]{2}{*}{$17 \mathrm{c} \mathrm{e} 15 \mathrm{c} / \mathrm{h}$} \\
\hline & SA5 $1 \mathrm{c}$ e $3 \mathrm{c} / \mathrm{h}$ & Sit. $63 \mathrm{c}$ e $2 \mathrm{c} / \mathrm{h}$ & SA7 $3 \mathrm{c} \mathrm{e} 1 \mathrm{c} / \mathrm{h}$ & & \\
\hline \multicolumn{6}{|c|}{ Projeção de Aulas dadas por bimestre, em 2014} \\
\hline \multicolumn{2}{|c|}{$1^{\circ}$ Bimestre } & $2^{\circ}$ Bimestre & $3^{\circ}$ Bimestre & \multicolumn{2}{|c|}{$4^{\circ}$ Bimestre } \\
\hline \multicolumn{2}{|c|}{20 aulas } & 18 aulas & 20 aulas & \multicolumn{2}{|c|}{16 aulas } \\
\hline
\end{tabular}

Fonte: Elaborado pelo autor a partir de São Paulo (2014) e Caderno de Campo

Já terceiro ano do Ensino Médio, dá-se início com uma atividade reflexiva sobre o preconceito que existe em relação à Filosofia e como muito, que têm reduzido a necessidade do conhecimento da Filosofia, do filosofar e do debate filosófico sem saber, em muitos casos, o que são estes elementos bem como a sua importância na sua vida.

Depois disso, parte-se da condição animal do ser humano para, daí, pensar na linguagem, como forma de fazer com que os discentes compreendam as interações humanas, como elas acontecem e as consequências do uso, deficitário ou de excelência, da linguagem nos espaços humanos. A posteriori colocam-se questões que envolvem a religião, a desigualdade e a política sob a ótica da Filosofia da Religião, de Platão e de Rousseau; a fim de elencar e problematizar estas esferas dentro do contexto histórico de cada um deles. 
Por conseguinte, no segundo volume do Material de Apoio ao Currículo do Estado de São Paulo (SÃO PAULO, 2014), investiga-se a relação que a Filosofia e a Ciência possuem e as (des) semelhanças nos métodos, abordagens e produções de conhecimento e, a seguir, é posto em pauta questões como o libertarismo, o determinismo e a concepção dialética da liberdade. Seguidamente a investigação é calcada na relação que a Filosofia possui com a Literatura e, por fim, acepções teóricas relativas à felicidade, nas diversas eras históricas. O Quadro 4 apresenta a disposição dos conteúdos, competências e habilidades esperadas para o terceiro ano e a quantidade de aulas disponíveis para a realização de tal demanda.

Quadro 4: Disposição dos conteúdos, habilidades e competências do $3^{\circ} \mathrm{EM}$

\begin{tabular}{|c|c|c|c|c|c|}
\hline \multicolumn{6}{|c|}{ Material de Apoio ao Currículo de São Paulo $-3^{\text {a }}$ série do Ensino Médio } \\
\hline \multicolumn{6}{|c|}{ Filosofia } \\
\hline \multicolumn{6}{|c|}{ Conteúdos (C), Competências e Habilidades (C/H) abrangidos por cada S.A } \\
\hline \multirow[t]{2}{*}{ Vol. 1} & SA1 4c e $7 \mathrm{c} / \mathrm{h}$ & SA2 4c e $7 \mathrm{c} / \mathrm{h}$ & SA3 $2 \mathrm{c} \mathrm{e} 3 \mathrm{c} / \mathrm{h}$ & SA4 4c e $4 \mathrm{c} / \mathrm{h}$ & $25 \mathrm{c}$ e $45 \mathrm{c} / \mathrm{h}$ \\
\hline & SA5 2c e $5 \mathrm{c} / \mathrm{h}$ & SA6 3c e $4 \mathrm{c} / \mathrm{h}$ & $\begin{array}{|lll|}\text { SA7 } & 2 \mathrm{c} & \mathrm{e} \\
8 & \mathrm{c} / \mathrm{h} & \text { aulas } \\
\end{array}$ & SA8 4c e $7 \mathrm{c} / \mathrm{h}$ & \\
\hline \multirow[t]{2}{*}{ Vol. 2} & SA12ce $6 \mathrm{c} / \mathrm{h}$ & SA2 3c e $7 \mathrm{c} / \mathrm{h}$ & SA3 3c e $6 \mathrm{c} / \mathrm{h}$ & SA4 2c e $7 \mathrm{c} / \mathrm{h}$ & $22 c$ e $48 \mathrm{c} / \mathrm{h}$ \\
\hline & SA5 2c e $6 \mathrm{c} / \mathrm{h}$ & SA6 4c e $7 \mathrm{c} / \mathrm{h}$ & SA7 3c e 5 c/h & SA8 3c e $4 \mathrm{c} / \mathrm{h}$ & \\
\hline \multicolumn{6}{|c|}{ Projeção de Aulas dadas por bimestre, em 2014} \\
\hline \multicolumn{2}{|c|}{$1^{\circ}$ Bimestre } & $2^{\circ}$ Bimestre & $3^{\circ}$ Bimestre & \multicolumn{2}{|c|}{$4^{\circ}$ Bimestre } \\
\hline \multicolumn{2}{|c|}{22 aulas } & 18 aulas & 18 aulas & \multicolumn{2}{|c|}{20 aulas } \\
\hline
\end{tabular}

Fonte: Elaborado pelo autor a partir de São Paulo (2014) e Caderno de Campo

É possível verificar, a princípio, que em todas as séries, o Material de Apoio ao Currículo do Estado de São Paulo (SÃO PAULO, 2014) exige grande conhecimento, inclusive técnico, do professor não apenas ao conteúdo filosófico, mas também didático, a fim que todos os discentes entendam, de maneira autônoma e esclarecida, o arcabouço filosófico.

Para tanto, são oferecidas uma série de atividades para cada etapa, SA, bimestre e semestre, sendo estas quantificadas e representadas no Quadro 5, o que corresponde a parte das demandas do professor no oferecimento da disciplina de Filosofia e, a partir destes dados, é possível refletir acerca do tempo disposto frente a quantidade de objetivos, conteúdos, competências, habilidades, etapas e atividades que devem ser supridas por todos frente ao processo de ensino/ aprendizagem. 
Quadro 5: Relação de Atividades por semestre frente ao tempo disponível

\begin{tabular}{|c|c|c|c|}
\hline $\begin{array}{c}\text { Séries/Anos } \\
\text { EM }\end{array}$ & $1^{\circ}$ Semestre (SM) & $2^{\circ}$ Semestre (SM) & Aulas dadas $\left(1^{\circ} / 2^{\circ} \mathrm{SM}\right)$ \\
\hline $1^{\circ}$ ano & $\begin{array}{l}8 \text { SA's } 108 \text { atividades } \\
\text { (52 que envolvem } \\
\text { diretamente o ensino } \\
\text { de língua portuguesa } \\
\text { e matemática) }\end{array}$ & $\begin{array}{c}8 \text { SA's } 107 \text { Atividades } \\
\text { (56 que envolvem direta- } \\
\text { mente o ensino de língua } \\
\text { portuguesa e matemá- } \\
\text { tica) }\end{array}$ & $38 / 32$ \\
\hline $2^{\circ}$ ano & $\begin{array}{l}8 \text { SA's } 111 \text { Atividades } \\
\text { (62 que envolvem } \\
\text { diretamente o ensino } \\
\text { de língua portuguesa } \\
\text { e matemática) }\end{array}$ & $\begin{array}{c}7 \text { SA's } 107 \text { Atividades } \\
\text { (53 que envolvem direta- } \\
\text { mente o ensino de língua } \\
\text { portuguesa e matemá- } \\
\text { tica) }\end{array}$ & $38 / 36$ \\
\hline $3^{\circ}$ ano & $\begin{array}{l}8 \text { SA's } 123 \text { Atividades } \\
\text { (61 que envolvem } \\
\text { diretamente o ensino } \\
\text { de língua portuguesa } \\
\text { e matemática) }\end{array}$ & $\begin{array}{l}8 \text { SA's } 91 \text { Atividades (50 } \\
\text { que envolvem direta- } \\
\text { mente o ensino de língua } \\
\text { portuguesa e matemá- } \\
\text { tica) }\end{array}$ & $40 / 38$ \\
\hline
\end{tabular}

Fonte: Elaborado pelo autor a partir de São Paulo (2014) e Caderno de Campo

Até mesmo em uma situação ideal, se pode constatar a impossibilidade de alcançar todos os objetivos pretendidos a serem cotejados por todos, uma vez que o professor possui pouco tempo necessário (tanto de preparo de aulas quanto de execução das mesmas), uma quantidade enorme de conteúdos, competências, habilidades que se materializam nas etapas e atividades propostas pelo Material de Apoio ao Currículo do Estado de São Paulo (SÃO PAULO, 2014) e que são impostas para os docentes realizar, delimitando a Filosofia.

\section{Considerações finais}

A Filosofia como disciplina, dentro da trajetória paulista, não tomou o seu caráter, ainda, de fato, filosófico (aquele que busca potencializar os indivíduos que dela se apetecem), mas apenas encontrara o seu caráter instrumentalista, ou seja, um meio para alcançar certa finalidade que não é da postura, da atitude e da reflexão filosófica.

Parte dos porquês disto é que, mesmo se partíssemos de uma situação ideal, na qual não haja nenhum absenteísmo docente, que professores e alunos estejam motivados a participar do processo de ensino/aprendizagem, percebendo a necessidade de aprender e de estudar, aonde que todos os envolvidos no processo gozassem de perfeitas condições de saúde física, psicológica seria uma demanda quase impossível de ser cumprida.

Esta constatação parte-se inicialmente do excessivo número de conteúdos, competências e habilidades que são esperados de serem assimiladas para a disciplina de Filosofia e que, em contrapartida, são disponíveis poucas aulas para que isto aconteça. 
Outro dos aspectos referentes a impossibilidade decorre da gana universal de ensinar de maneira equânime os alunos que, mesmo se as aulas acontecessem no ideal acima especificado, os alunos são construídos em esferas sociais, políticas, econômicas diferentes e em processos interacionais diversos e, em muitos casos, até divergentes e, também por isso, possuem representações e visões distintas/distantes uma das outras.

Por outro lado, o percurso previsto pelo currículo e pelo material oficial são muito interessantes, mas que precisam ser reavaliados e readequados e, igualmente, o número de aulas usadas para o ensino de Filosofia para, deste modo, suprir aquilo que é demandado.

\section{Referências}

ASPIS, Renata Pereira Lima; GALLO, Silvio Donizetti de Oliveira. Ensinar Filosofia: um livro para professores. São Paulo: Atta Midia e Educação, 2009.

BITTENCOURT, Renato Nunes. Pela afirmação da importância da Filosofia no Ensino Médio Brasileiro. Revista Espaço Acadêmico, São Paulo. nº 171 - Agosto de 2015.

GONÇALVES, Julio César. A filosofia e o filosofar institucionalizado: um olhar sobre o ensino filosófico no ensino médio. 2014. 94 f. Dissertação (Mestrado em Educação). Faculdade de Ciências e Tecnologia, Universidade Estadual Paulista "Júlio de Mesquita Filho". Presidente Prudente, 2014.

GIL, Antônio Carlos. Como elaborar projetos de pesquisa. 4. ed. São Paulo: Atlas, 2002.

KOHAN, Walter. Perspectivas atuais do ensino de Filosofia no Brasil. In: FÁVERO, Altair Alberto;

RAUBER, Jaime José; KOHAN, Walter Omar (Org.). Um olhar sobre o ensino de Filosofia. ljuí: Unijuí, 2002. p. 21- 40.

RANCIĖRE, Jacques. O mestre ignorante: cinco lições sobre a emancipação intelectual. Tradução de Lílian do Valle - 2 ed. - Belo Horizonte: Autêntica, 2004.

RODRIGUES, Zita Ana Lago. O ensino da Filosofia no Brasil no contexto das políticas educacionais contemporâneas em suas determinações legais e pragmáticas. Educar em Revista, Curitiba, Brasil, n. 46, p. 69-82, out./dez. 2012. Editora UFPR. Disponível em: <http://www.scielo.br/pdf/er/n46/ n46a06.pdf>. Acesso: 13 fev. 2017.

SÁ JÚNIOR, Lucrécio Araújo de. Reflexões sobre o ensino de Filosofia no Ensino Médio. HOLOS, Rio Grande do Norte. Ano 26, Vol. 3. 2010. Disponível em: <http://www2.ifrn.edu. br/ojs/index.php/ HOLOS/article/view/403>. Acesso: 16 ago 2016.

SÃO PAULO (ESTADO) SECRETARIA DA EDUCAÇÃO. Currículo do Estado de São Paulo: Ciências Humanas e suas tecnologias/ Secretaria da Educação; coordenação geral, Maria Inês Fini; coordenação de área, Paulo Miceli. - São Paulo: SEE, 2010. 
do Estado de São Paulo: Caderno do Professor: filosofia, ensino médio/ Secretaria da Educação; coordenação geral, Maria Inês Fini; equipe; Adailton Luís Martins, Luiza Chirstov, Paulo Miceli - São Paulo: SEE, 2014.

SEVERINO, Antônio Joaquim. Metodologia do trabalho científico. 22. ed. São Paulo: Cortez, 2002.

\section{Notas}

1 Hoje conhecida como Progressão Continuada.

${ }^{2}$ A escolha desse período se dá por decorrência de ser esse o período em que foi feito a pesquisa que aqui é esboçada.

${ }^{3}$ Conceito elaborado por Rodrigo (2009) para caracterizar as escolas públicas.

${ }^{4}$ É uma das avaliações externas de larga escala de terceira geração que existe em nosso país e, como denominador comum, todas as avaliações de terceira geração trazem em seu bojo forte responsabilização das escolas a partir dos resultados alcançados nessa avaliação. Cabe ressaltar que é denominada de avaliação externa de larga escala de terceira geração, pois, antes da estrutura do SARESP, houve a formulação de outras duas avaliações externas: Sistema de Avaliação da Educação Básica (SAEB), considerada como avaliação de primeira geração por ter como objetivo e finalidade mensurar a qualidade da educação, mas sem divulgar os resultados alcançados e a Prova Brasil, de segunda geração, que além de ter os mesmos objetivos do SAEB, ainda, há a divulgação dos resultados alcançados por tal instrumento de coleta de dados.

${ }^{5}$ São fragmentos do currículo e que, por sua vez, são divididos por etapas, com conhecimentos priorizados em cada momento e, por conseguinte, metodologias propostas, sistemas de avaliação e previsão de número aulas que são necessárias para execução de uma parcela do currículo.

${ }^{6}$ Esta demarcação é pensada a partir de todo o roteiro previsto, pois são 16 SAs para 4 bimestres, com exceção do quarto bimestre do segundo ano do ensino médio, que são 3 SAs pois são 15 SAs neste período.

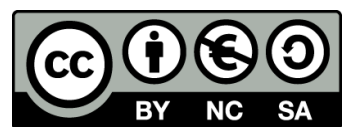

This work is licensed under a Creative Commons Attribution-NonCommercial 4.0 International (CC BY-NC 4.0) 